\title{
Damage to Teluk Palu Bridge in the 2018 Sulawesi Earthquake, Indonesia
}

\author{
Kenji Kosa ${ }^{1, *}$, Hendra Setiawan ${ }^{2}$, Masakatsu Miyajima ${ }^{3}$, Yusuke $\mathrm{Ono}^{4}$, and Masaho \\ Yoshida $^{5}$ \\ ${ }^{1}$ Kyushu Institute of Technology, Sensui 1-1, Tobata, Kitakyushu, Fukuoka, 804-8550 Japan \\ ${ }^{2}$ Tadulako University, Bumi Tadulako Tonda Campus, Palu, Central Sulawesi, 941182 Indonesia \\ ${ }^{3}$ Kanazawa University, Kakuma-machi, Kanazawa, Ishikawa, 920-1192 Japan \\ ${ }^{4}$ Tottori University, Koyamacho Minami 4-101, Tottori, 680-8552 Japan \\ ${ }^{5}$ National Institutte of Technology, Fukui College, Geshi, Sabae, Fukui, 916-8507 Japan
}

\begin{abstract}
The authors conducted a field survey in the affected area of the 2018 Sulawesi Earthquake, mainly focusing on the damage occurred to the Teluk Palu Bridge in Palu City. It was found that the area around the bridge received approximately 200 gal acceleration and 3 to $6 \mathrm{~m}$ tsunami height. From the traces of the tsunami, we estimated that the tsunami reached up to the girder but not up to the arch rib of the bridge. The arch ribs sustained buckling and displaced 2 to $5 \mathrm{~m}$ into the water. The main cause of bridge collapse was the earthquake force as local eyewitnesses said the bridge collapsed immediately after the earthquake and before the arrival of the tsunami. In terms of earthquake-resistant design, the following three problems were identified regarding this arch bridge: resisting capacity of the arch rib, resisting capacity of the bearing system, and design concept about the seating length at the pier.
\end{abstract}

\section{Introduction}

A large earthquake with a magnitude of $7.5 \mathrm{Mw}$ occurred near Palu City in Sulawesi Island, Indonesia on September 28, 2018. Due to the earthquake and the ensuing tsunami, a large number of buildings and structures, including a mosque, hospitals, and schools, were severely damaged. The area's symbolic Teluk Palu Bridge, which is a simple two-span steel arch bridge, also collapsed.

The authors conducted a damage survey around Palu City for four days from November 16 to 20 . In this paper, we will present the results of the survey and the follow-up study, mainly focusing on the observed damage and the cause of collapse of the bridge.

\section{Earthquake motion and generation of tsunami}

\footnotetext{
${ }^{*}$ Corresponding author: kosa.kenji383@mail.kyutech.jp
} 


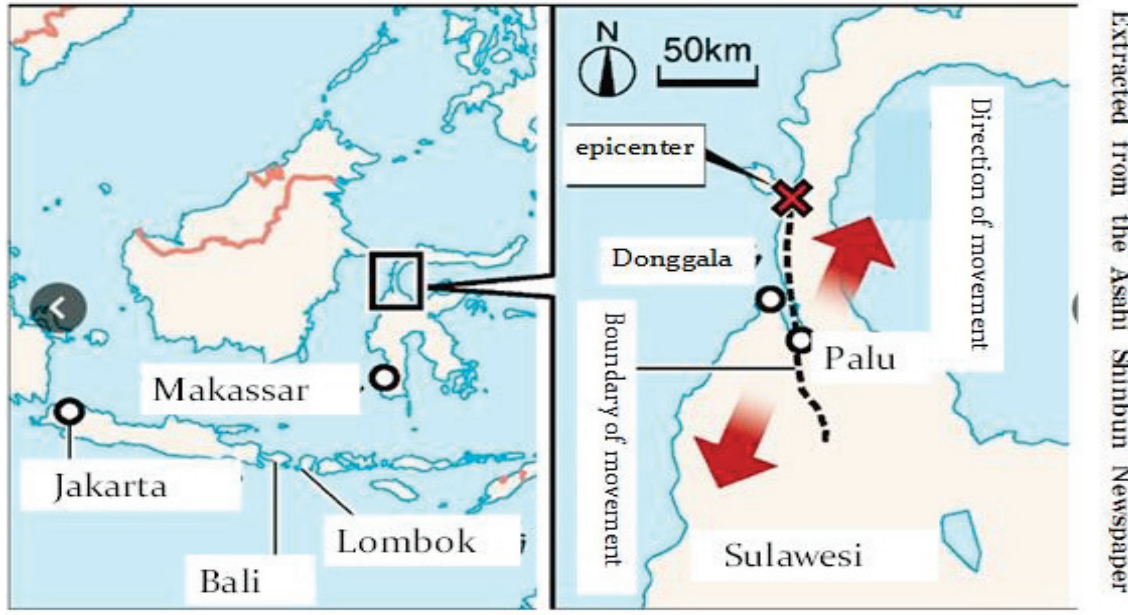

Fig. 1. Map of the Sulawesi Earthquake

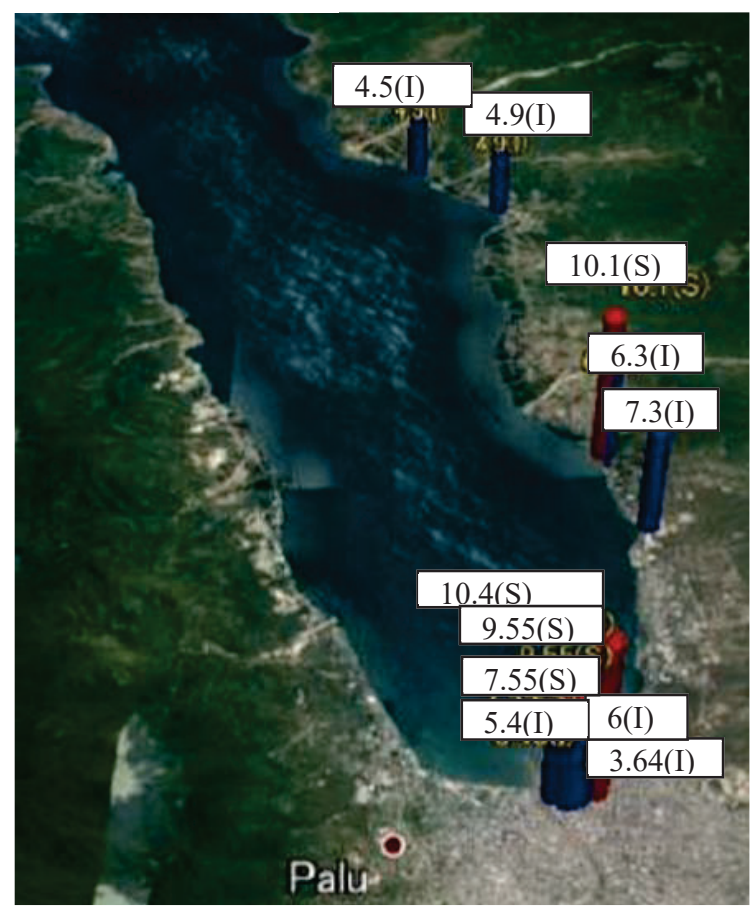

Fig. 2. Inundation height and splash height measured by Imamura et al.

Figure 1 shows the map of the Sulawesi Earthquake, including the location of the epicenter, and directions of crustal movement ${ }^{[1]}$. According to the analysis by the Geographical Information Authority of Japan, the Palu-Koro Fault stretches in the north-south direction, and the west side of the fault moved to the south direction and the east side to the north direction. The lateral displacement around Palu was quite large, about $5 \mathrm{~m}$. This earthquake was the type of earthquake called the left-lateral strike-slip. In this type of earthquake, a large tsunami is not normally triggered because a vertical slip is usually small. However, 


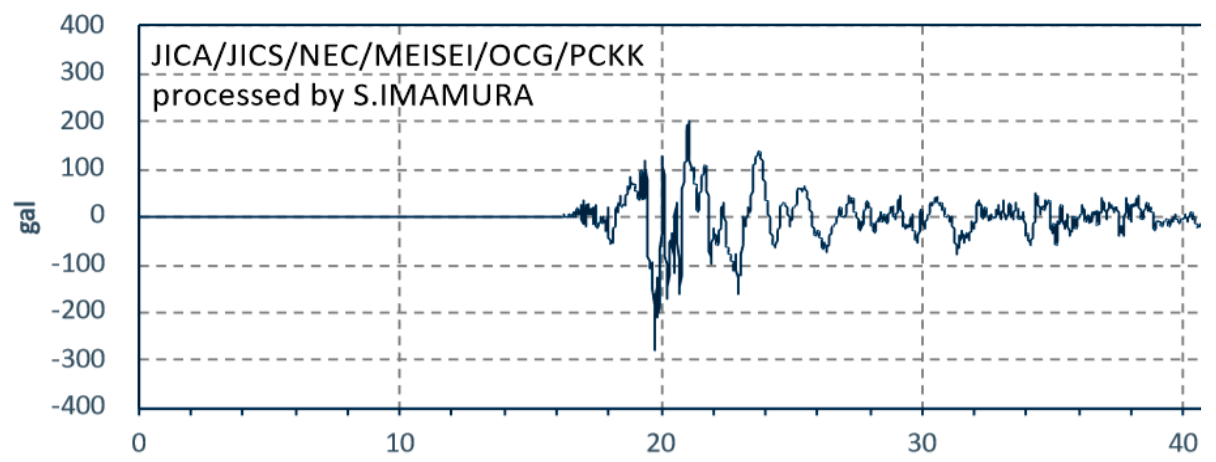

Fig. 3. Waveform in the N-S direction observed in Palu City .

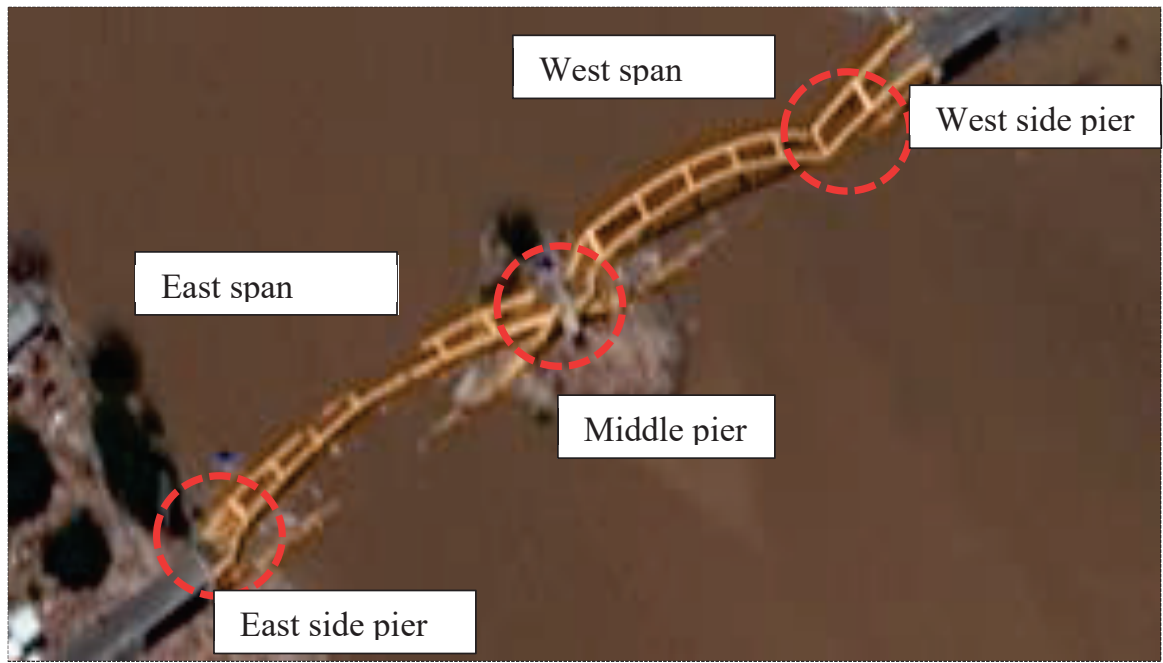

Fig. 4. Damage to the east and west spans of the Teluk Palu Bridge

the tsunami that reached Palu was as high as 3-6 m.

Regarding this phenomenon, Imamura of Tohoku University inferred that numerous landslides occurred at both on-land and underwater slopes and it caused an extreme fluctuation in the water level of the bay, triggering the generation of the tsunami.

Figure 2 shows the splash height and the inundation height measured by Imamura et al. The splash height and the inundation height without tidal level correction are indicated in red and blue, respectively. The splash height and the inundation height measured in the bay area were 7-10 $\mathrm{m}$ and 3-7 m, respectively. The inundation height around the Telk Palu Bridge located in the center area of Palu City was 3-6 $\mathrm{m}^{[2]}$. The inundation area was limited to within 200-300 $\mathrm{m}$ from the coastline.

Using video images available on the Internet, we estimated the tsunami velocity at several locations near the bridge. According to our estimation, the average tsunami velocity was about $7 \mathrm{~m} / \mathrm{s}$. It is a quite high velocity compared with a typical tsunami velocity 3-5 $\mathrm{m} / \mathrm{s}$ when the tsunami height is 3-5 $\mathrm{m}$, which was observed in the Great East Japan Earthquake in 2011.

Figure 3 shows the waveform in the N-S direction recorded in Palu City and processed by Imamura et al. A maximum acceleration of 200 gal continued for at least 40 seconds. 
The maximum acceleration in the E-W direction was also 200 gal and it also continued for at least 40 seconds $^{[3]}$.

\section{Outline of Teluk Palu Bridge}

The Teluk Palu Bridge is a $252 \mathrm{~m}$-long steel arch bridge with two spans $(126+126 \mathrm{~m})$. It connects the east and west sides of Palu City with a population of 350,000 . The height of the arch is $20 \mathrm{~m}$ and the width of the roadway is $9 \mathrm{~m}$. A walkway is placed on both sides of the roadway. According to bridge experts in Indonesia, the bridge construction was ordered by the Palu city government and completed by the steel engineering company Waagnerbiro in Austria.

When visiting the site, we were unable to observe the damage in detail because the bridge was being demolished. Therefore, we inferred the damage based on the information obtained from bridge experts in Indonesia and other related materials. Figure 4 shows the damage to the east and west spans of the bridge ${ }^{[4]}$. Figure 5 shows a closeup picture of the buckled arch rib ${ }^{[5]}$. These pictures were taken on October 1, three days after the earthquake. These pictures show that buckling occurred at three positions. Namely, buckling occurred to the intermediate member between the arch rib base and the lateral beam located on the east side pier of the east span. In the case of the west span, buckling occurred to the intermediate member between the arch rib base and the lateral beam located on the middle pier and to the second lateral beam from the west side pier. In particular, the intermediate member on the east side pier sustained serious buckling at about $5 \mathrm{~m}$ from the arch rib base due to the movement in the transverse direction.

Figure 6 shows the positions of the bridge before and after the earthquake. The following information was obtained from a university professor in Palu. After the earthquake, the east side of the east span and the west side of the west span displaced to the mountain side about $2 \mathrm{~m}$. In addition, the center portion of the bridge, namely, the west side of the east span and east side of the west span located above the middle pier on the sandbank displaced to the mountain side about $5 \mathrm{~m}$. The displacement of the center portion of the bridge is also seen in Fig. 4

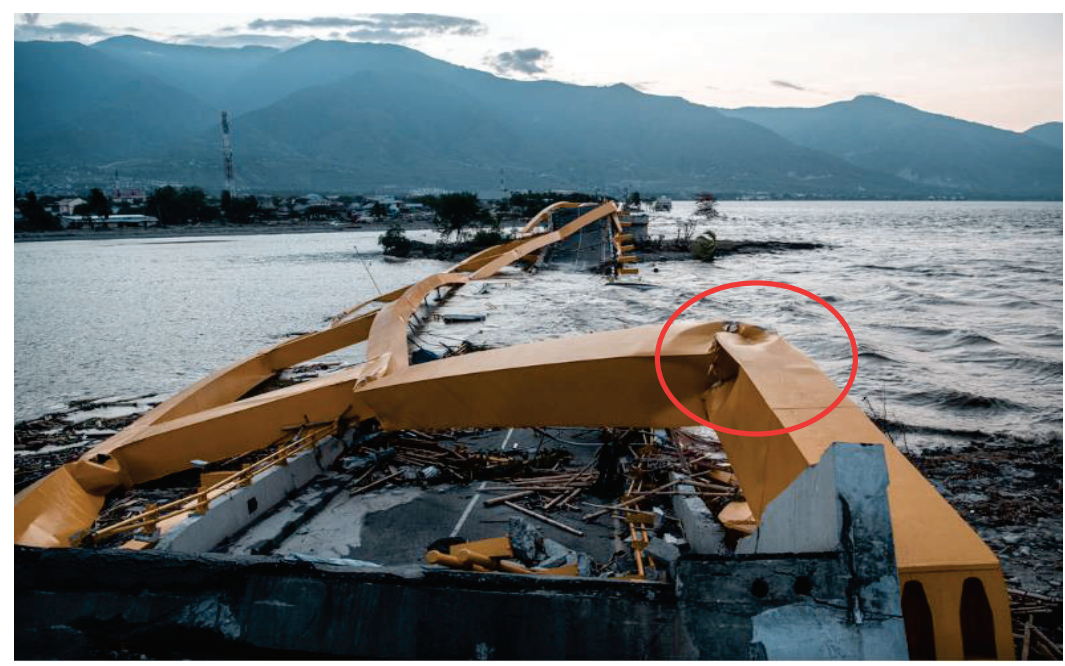

Fig. 5. Closeup picture of buckled arch rib 

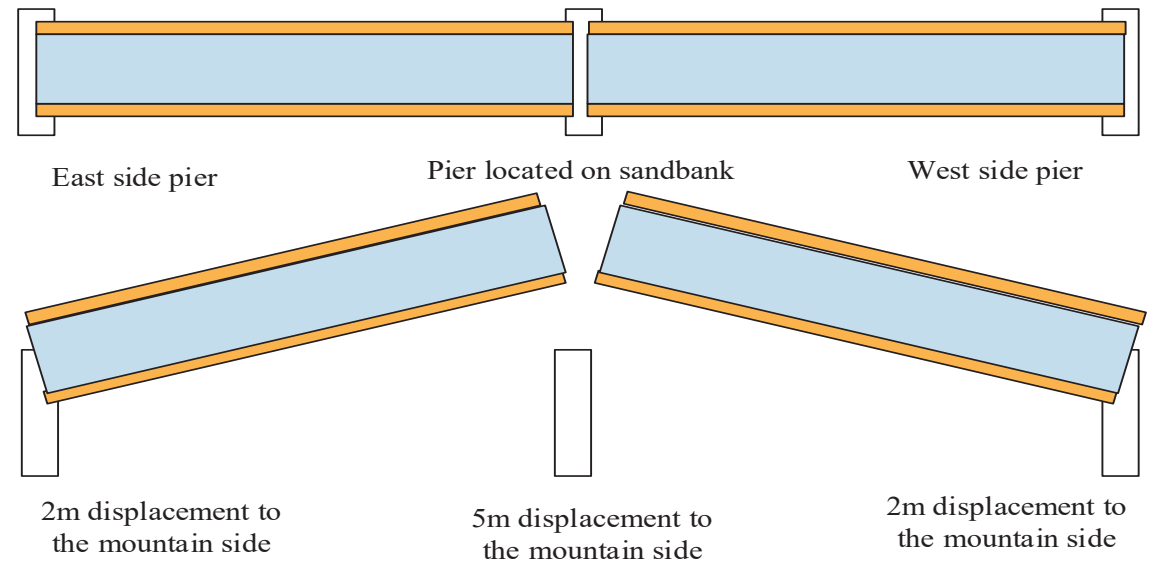

Fig. 6. Positions of the bridge before and after the earthquake

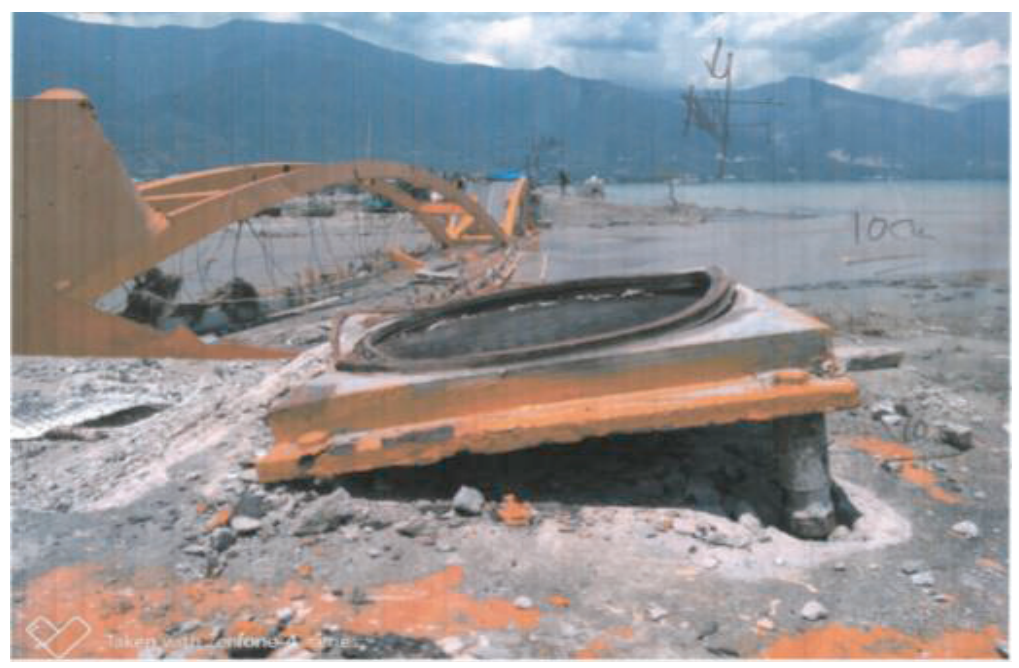

Fig. 7. Damaged bearing system at the middle pier

\section{Causes of damage}

As the cause of collapse of the Teluk Palu Bridge, the earthquake force and the tsunami force are considered. As a first step, the authors looked for the tsunami traces around the bridge to identify the tsunami height. From the accumulated sand and debris around the simple girder adjacent to the west span, we presumed that the tsunami did not reach up to the arch rib, although the splash may have reached up to the girder below the arch rib. We also obtained information from local eyewitnesses. They said that there was about 5 -minute time lag between the earthquake and the tsunami, and the bridge collapsed before the 


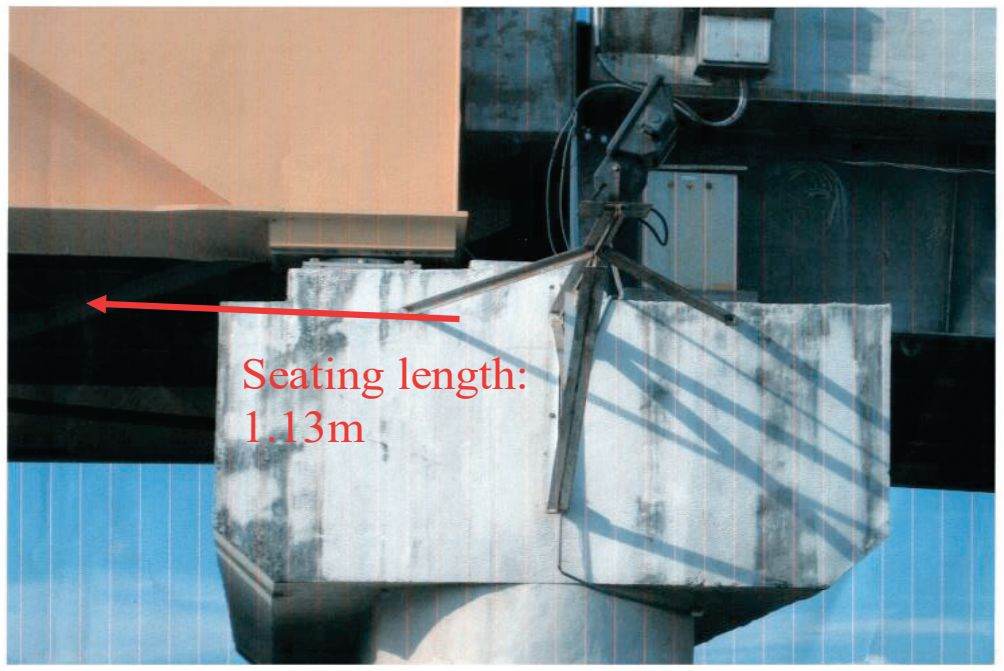

Fig. 8. Bearing system at the west side pier

arrival of the tsunami. From this information, we assumed that the earthquake force was the main cause of bridge collapse.

Figure 7 shows the damage to the bearing system at the middle pier located on the sandbank. It is a small-sized system called BPA (Bearing System A type). It is uncommon that such a small-sized bearing system is adopted for an arch bridge. This bearing system was damaged as the superstructure moved. Figure 8 shows the bearing system and the pier at the west end of the west span. It is seen that the bearing system is quite small compared with the size of the bridge. It is also seen the seating length at the pier is not sufficient.

As shown in Fig. 3, the maximum acceleration of the earthquake was 200 gal. This level of acceleration is not strong enough to cause the collapse of the bridge. The seating length should be $1.13 \mathrm{~m}$ for this length of bridge if the Japanese design code is applied.

The following two are considered as the possible process behind the collapse of the bridge. The earthquake force acted on the superstructure in the transverse direction, as shown in Fig. 9 (The picture of the bridge was extracted via the Internet ${ }^{[5]}$ ). As a result, 1) The arch rib buckled due to the earthquake force in the transverse direction and moved largely to that direction. Then, the whole superstructure also moved to that direction and fell into the river, partly because of the insufficient seating length at the pier.

2) The bearing system was damaged when the earthquake force acted on the superstructure in the transverse direction and the superstructure moved to that direction. As the seating length at the pier was not sufficient, the bridge fell into the water.

For further clarification, we need to evaluate the resisting capacity of the bridge members by obtaining design drawings of the bridge. In particular, we need to deepen the following three design problems.

a) Resisting capacity of the arch rib, particularly the resisting capacity of the member at a position about $5 \mathrm{~m}$ from the arch base.

b) Performance of the bearing system under earthquake loading

c) Design concept for the seating length at the pier 


\section{Resisting capacity of the bridge against tsunami}

We evaluated the resisting capacity of the arch rib against a tsunami by comparing a wind load and a tsunami load that would act on the arch rib. A wind load and a tsunami load that would act on the arch rib are expressed by Equations (1) and (2), respectively.

$$
\begin{aligned}
& P_{1}=0.5 C_{\mathrm{d} 1} \rho_{1} V_{1}^{2} A_{1} \\
& P_{2}=0.5 C_{\mathrm{d} 2} \rho_{2} V_{2}^{2} A_{2}
\end{aligned}
$$

where, $P$ : acting load $(\mathrm{kN}) ; C_{d}:$ drag coefficient; $\rho_{2}:$ density $\left(\mathrm{kg} / \mathrm{m}^{3}\right) ; \quad V:$ velocity $(\mathrm{m} / \mathrm{s})$; and $A$ : area that receives load

For simplification, we assumed $C_{\mathrm{d} 1}=C_{\mathrm{d} 2}, V_{1}=50 \mathrm{~m} / \mathrm{s}, \rho_{1}=1.293\left(\mathrm{~kg} / \mathrm{m}^{3}\right), V_{2}=5 \mathrm{~m} / \mathrm{s}, \rho_{2}$ $=1,030\left(\mathrm{~kg} / \mathrm{m}^{3}\right)$, and $A_{1}=A_{2}$. Then $P_{2}=8 P_{1}$ is derived.

This means that if the tsunami height rises up to $3 \mathrm{~m}$ position of the arch rib height $(20 \mathrm{~m})$, the resulting tsunami load exceeds the wind load.

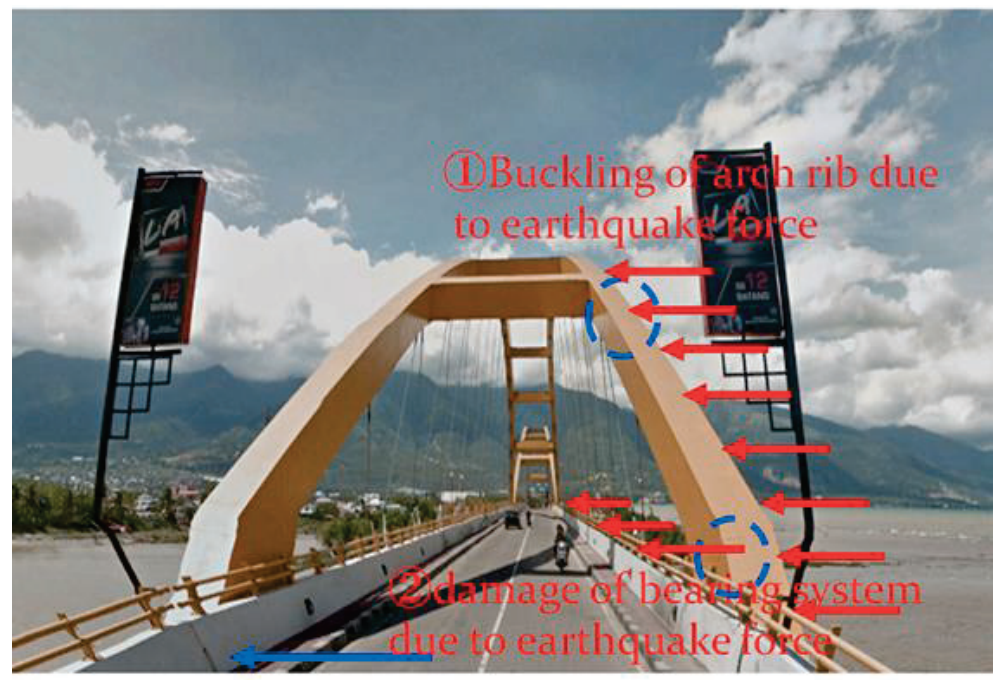

Fig. 9. Direction of earthquake force

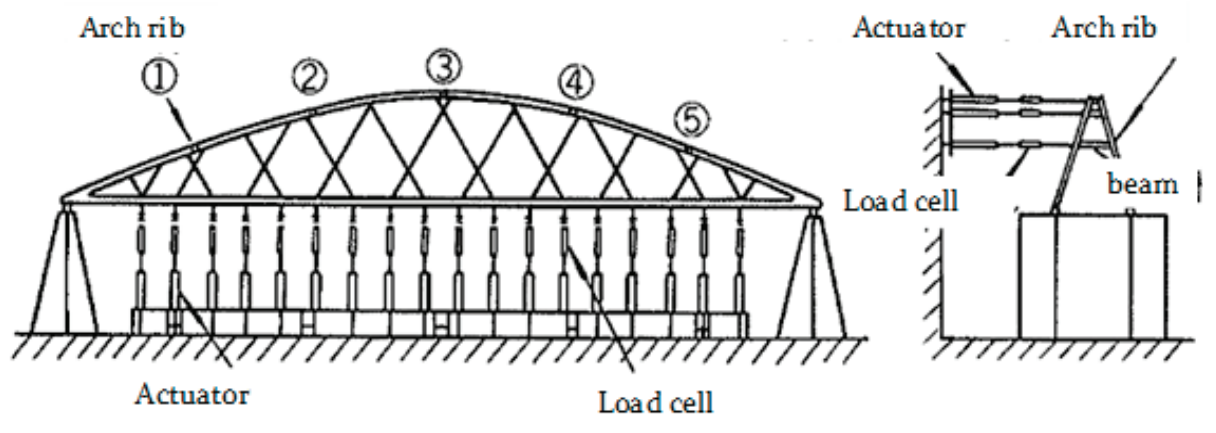
(a) side View
(b)Cross sectional view

Fig. 10. Experimental setup 
From the above results, we can say that the tsunami effect should be evaluated in detail in the case of an arch bridge which is located near the sea and does not have a sufficient arch height compared with the expected tsunami height.

\section{Evaluation of earthquake-resisting capacity}

To evaluate the resisting capacity of an arch bridge against an earthquake force, the results of an experiment conducted by the Hanshin Expressway in Osaka was utilized ${ }^{[6]}$. In that experiment, a 1/30 scale model of the Shin Hamadera Bridge was tested. It is a Nielsen Rohse type arch bridge with a span length of $254 \mathrm{~m}$. The results of this experiment were used to compare the buckling mode of the arch rib with that of the Teluk Palu Bridge.

In the experiment, two types of specimens were tested: Specimen No. 1 for vertical loading and Specimen No. 2 for combined vertical and horizontal loading (Fig. 10).

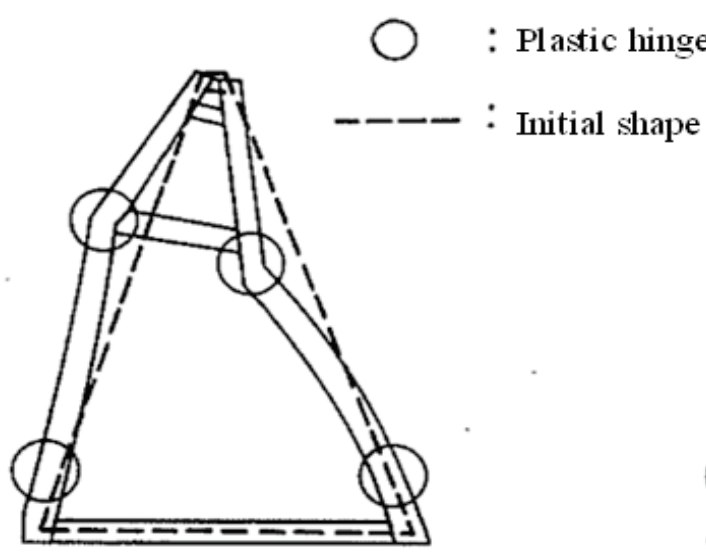

(a) Specimen No. 1

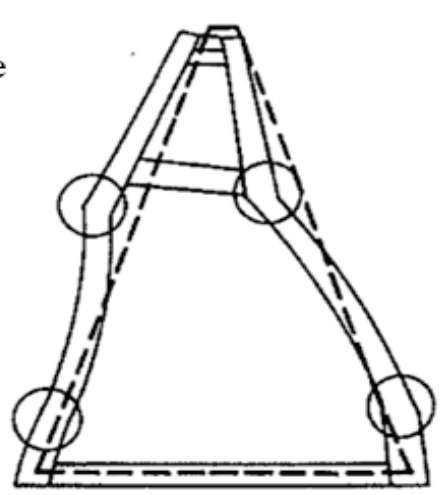

(b) Specimen No.2

Fig. 11. Failure mode of specimens

Table 1. Comparison of ultimate loads (Unit: $\mathrm{kN}$ )

\begin{tabular}{|l|l|l|l|}
\hline \multirow{2}{*}{ No.1 } & Load type & $\begin{array}{l}\text { Experimental } \\
\text { load }\end{array}$ & $\begin{array}{l}\text { Analytical } \\
\text { load }\end{array}$ \\
\cline { 2 - 4 } & $\begin{array}{l}\text { Vertical load } \\
\text { Horizontal } \\
\text { load }\end{array}$ & 368 & 361 \\
\cline { 2 - 4 } & $\begin{array}{l}\text { Combined } \\
\text { load }\end{array}$ & 368 & - \\
\hline No.2 & Vertical load & 180 & 361 \\
\cline { 2 - 4 } & $\begin{array}{l}\text { Horizontal } \\
\text { load }\end{array}$ & 53.9 & 180 \\
\cline { 2 - 4 } & $\begin{array}{l}\text { Combined } \\
\text { load }\end{array}$ & 187.9 & 27.5 \\
\hline
\end{tabular}


An experimental setup for Specimens No.1 and No. 2 are shown in Figs. 10 (a) and 10 (b), respectively. For Specimen No. 1, uniform vertical load was applied to the lower chord in an incremental manner until the failure of the specimen, using 18 actuators. For Specimen No. 2, horizontal load equivalent to the wind load was applied to the arch rib using five actuators while maintaining a uniform vertical load equivalent to 1.3 times the design dead load.

Table 1 compares the ultimate loads obtained from the experiment and the elasto-plastic finite analysis. It is seen that the combined ultimate load (vertical + horizontal) obtained from the experiment was in good agreement with that of the analysis.

Figure 11 compares the failure mode of the two specimens. Buckling occurred near the base of the arch rib and around the lateral beam in both specimens. The failure mode of Specimen No. 2 under combined vertical and horizontal loading is quite similar to that of the Teluk Palu Bridge. As the analytical results are well coincided with the experimental results, numerical analysis can be applied to the evaluation of earthquake behaviour of arch bridges.

\section{Conclusions}

From the field survey and follow-up study regarding the 2018 Sulawesi Earthquake, the following results were obtained:

1) Due to the $7.5 \mathrm{Mw}$ earthquake, the area around the Teluk Palu Bridge most likely received about 200 gal acceleration and 3 to $6 \mathrm{~m}$ tsunami height.

2) We estimated that the tsunami probably reached up to the girder of the bridge but not up to the arch rib based on the tsunami traces observed on the adjacent simple girder.

3) There was a 5-minute time lag between the occurrence of the earthquake and the arrival of the tsunami. Two local witnesses saw the collapse of the bridge immediately after the earthquake. Therefore, the main cause of the bridge collapse was the earthquake force.

4) In terms of earthquake resistant design, the following three design problems need further investigation: resisting capacity of the arch rib, resisting capacity of the bearing system, and design concept for the seating length at the pier.

\section{References}

1. Article from Asahi Shimbun Newspaper, "A number of localized tsunamis occurred?", Oct. 7 (2018)

2. A. Muhari, F. Imamura, T. Arikawa, B. Afriyanto, "Finding of the unexpected tsunami due to the strike-slip fault at central Sulawesi, Indonesia on Sept. 28, from the preliminary field survey at Palu", Report by IRIDeS at Tohoku Univ.(2018)

3. BMKG and JICA, Palu Earthquake Strong Motion Waveform by Observation System Developed by Japan (2018)

4. New York Times online news via the Internet, Oct (2018)

5. BBC online news via the Internet, Oct (2018)

6. M. Matsumoto, F. Yasuda, H. Aketa, S. Kaneko, "Design and Construction of Japan's largest Nielsen Rohse type Shin Hamadera Bridge”, J. of Brdg \& Fndn, 121-125, Aug (1991) 